\section{Screening is dead. Long live screening!}

\author{
Ben Clarsen, ${ }^{1,2}$ Hilde Moseby Berge ${ }^{2}$
}

Most of us have done it, right? Screening athletes for injury risk has become a normal part of our jobs as sport and exercise medicine clinicians. Why? Most likely because targeting high-risk athletes with individualised prevention programmes is an extremely attractive idea. Unfortunately, however, it may also be a misguided idea. Professor Roald Bahr illustrates just how unrealistic it is to identify which athletes will and will not get injured using current risk factor screening tests. ${ }^{1}$

Similarly, Wright et $a l^{2}$ highlight the inability of the extremely popular functional movement screen to predict injury. These papers challenge the entire concept of individually targeting high-risk athletes to prevent injury. We expect these papers to be real game changers-you will not screen without thinking about them.

So are standardised musculoskeletal assessments a waste of time? We think not. In fact, they remain a key element of our periodic health evaluations of Norwegian Olympic and Paralympic athletes. We perform musculoskeletal assessments to identify current 'under-the-radar' injuries, assess the rehabilitation status of previous injuries and establish future return-to-sport benchmarks for healthy athletes. Identifying who will get injured (and who will not) based on risk factor testing is wishful thinking for the foreseeable future. Nevertheless, when it comes to musculoskeletal screening, we urge readers not to throw the baby out with the bath water.

\section{MUCH NEEDED EVIDENCE ON RETURN TO SPORT}

Return to sport is a hot topic, ${ }^{3}$ yet in many cases the lack of high-quality research evidence to guide our decision-making can be

${ }^{1}$ Oslo Sports Trauma Research Center, Norwegian School of Sport Sciences, Oslo, Norway; ${ }^{2}$ The Olympic Elite Sports Programme (Olympiatoppen), Oslo, Norway

Correspondence to Dr Ben Clarsen, Oslo Sports Trauma Research Center, Norwegian School of Sport Sciences, Postboks 4014, Ullevål Stadion, Oslo 0806, Norway; ben.clarsen@nih.no extremely frustrating. That is why we expect the paper by Dr Hege Grindem et $a l^{4}$ to cause a huge splash. Their findings should give pause for thought to every athlete planning to return to high-level jumping, pivoting and cutting sports after ACL injury. The authors provide a strong case against premature return to sport, showing that, for every month of rehabilitation completed up to 9 months postinjury, the risk of reinjury falls by $51 \%$. Clinicians seeking to put the brakes on overly enthusiastic athletes will certainly appreciate this quality evidence.

\section{PREVENTION OF COMMON ILLNESSES IN SPORT-IMPORTANT! (FOR SOME)}

The extent to which common illnesses such as upper respiratory tract and gastrointestinal infections pose a problem for athletes varies substantially between sports. In a recently-published study of football players in the Norwegian, Swedish and English Premier Leagues, Bjørneboe et $a l^{5}$ found that illness is only a minor contributor to the total health burden, with players getting sick on average once every two seasons. In contrast, surveillance data from the Norwegian Olympic and Paralympic team show that, in certain sports, such as swimming, rowing and cross-country skiing, common illnesses have a far greater impact on athletes' participation and performance than do injuries (unpublished data-for methods). ${ }^{6}$ In these sports, developing, testing and implementing illness prevention strategies should be among our main priorities.

Dr Ida Svendsen et $a l^{7}$ identified a number of risk factors for gastrointestinal and upper respiratory tract symptoms among elite cross-country skiers, such as season and competition period, training behaviours and international air travel. The authors suggest a number of novel prevention strategies, such as avoiding air travel immediately after racing, when athletes' immune function is already compromised. This practical suggestion should certainly be tested.

\section{COME AND JOIN THE HERD}

The 13th Scandinavian Congress of Medicine and Science in sports will be held this November at the beautiful Norefjell resort near Oslo. This fantastic congress, renowned for both its scientific and social programmes, is held in English and international guests are especially welcome. Do not forget your dancing shoes-or your hiking boots. Who knows, you might even spot one of the local reindeer herds, as did amateur photographer Arnhild Olsen, who snapped our beautiful cover image. We hope to see you there!

Twitter Follow Benjamin Clarsen at @benclarsen and Hilde Moseby Berge at @HildeMBerge

Competing interests None declared.

Provenance and peer review Not commissioned; internally peer reviewed.

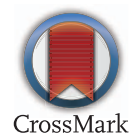

To cite Clarsen B, Moseby Berge H. Br I Sports Med 2016;50:769.

Accepted 21 May 2016

Br J Sports Med 2016;50:769.

doi:10.1136/bjsports-2016-096475

\section{REFERENCES}

1 Bahr R. Why screening tests to predict injury do not work —and probably never will...: a critical review. $\mathrm{Br}$ J Sports Med 2016;50:776-80.

2 Wright AA, Stern B, Hegedus EJ, et al. Potential limitations of the Functional Movement Screen: a clinical commentary. Br J Sports Med 2016;50: 770-1.

3 Ardern C, Glasgow P, Schneiders A, et al. Consensus statement on return to sport from the First World Congress in Sports Physical Therapy, Bern. Br J Sports Med 2016;50:850-61.

4 Grindem H, Snyder-Mackler L, Moksnes H, et al. Simple decision rules can reduce reinjury risk by $84 \%$ after $\mathrm{ACL}$ reconstruction: the Delaware-Oslo $\mathrm{ACL}$ cohort study. Br J Sports Med 2016;50:804-8.

5 Bjørneboe J, Kristenson K, Waldén M, et al. Role of illness in male professional football: not a major contributor to time loss. Br J Sports Med 2016;50:699-702.

6 Clarsen B, Rønsen 0, Myklebust G, et al. The Oslo Sports Trauma Research Center questionnaire on health problems: a new approach to prospective monitoring of illness and injury in elite athletes. $\mathrm{Br} J$ Sports Med 2014;48:754-60.

7 Svendsen IS, Taylor IM, Tønnessen E, et al. Training-related and competition-related risk factors for respiratory tract and gastrointestinal infections in elite cross-country skiers. Br J Sports Med 2016;50:809-15. 